\title{
Preface: why this book?
}

\author{
Daniel McDowell
}

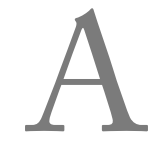

$s$ a non-scientist and therefore without the informed appreciation of the marvel that is the great telescope and its associated technology, my reaction on first visiting Birr was, I suspect, a common one, which is: 'How and why did this happen here, of all places; a large castle, an aristocratic family, world-class gardens and in a relatively remote situation - bang in the middle of Ireland, midway between Dublin and Cork?'

The more familiar I became with the Rosse and Birr heritage, the more enthralled was I with the story of the long and complex attempts to build the telescope(s) and with the people - William, the 3rd Earl, and his wife, Mary, who together made a working reality of William's ambitious ideas which other men of scientific standing claimed were not achievable. There were, of course, other realities to their lives, including that of being parents who produced four very able sons, in large measure educated at home and three of whom made significant careers in what, for the sake of brevity, we will call technology. Laurence (1840-1908) the eldest became, like his father, an astronomer of importance and also, like his father, an inventive technologist; Clere (1851-1923), became an engineer of note who for some time worked with the youngest brother, Sir Charles Parsons (1854-1931), whose life and work in engineering was, by any standards, memorable.

The marriage, in 1836, of William Parsons and Mary Field of Heaton, Bradford, brought together two imaginative, inquisitive and energetic people who shared and encouraged each other's enthusiasms and projects. The immediate context for their lives and achievement is most obviously determined by the space and resources provided by a large estate, the status and influence of William, and the necessary catalyst of Mary's large inheritance. The broader and more elusive context is that of the 
nature of Irish life and culture, including science, and the vibrancy and confidence of Victorian Britain, which included a growing fascination with science, technology and manufacturing.

A danger involved in this 'contextualisation' is that the emphasis may all too easily be given to the more easily understood context itself, to the detriment of the 'technical' and scientific nature of the development and of the principles underlying it. This book certainly aims to examine the context(s) - my initial 'how and why' - and also to describe the development and the issues, some technical, some not, which will, I hope, allow the reader to appreciate the problems, the excitement and the outcomes involved in William's achievement in creating and deploying the 'Leviathan of Birr'.

There are, of course, existing books and articles which cover many aspects of the life and work of William and Mary; I have read most of them, besides spending many hours in the extensive archives held at Birr and, fascinating though most of the published work is, I realised, as a scientific layman, that there was no work which set out to describe and evaluate the Rosse-Birr phenomena. This book was conceived as an attempt to do that by bringing together eminent scholars of the history of science with interested and non-scientific observers. I was delighted with the initial response when I floated the proposal, and even more delighted when, at the suggestion of Professor Schaffer, Dr Charles Mollan agreed to edit the work. As some readers will know, Charles has written extensively on the history of science in Ireland; his role as editor, involving the usual pursuit of contributors for their essays, has succeeded in bringing together a very disparate group of people, including several of great repute and others, like myself, who have something different to contribute, which we hope may be of some value. 